\title{
Saint Jude Children's Research Hospital
}

National Cancer Institute

\section{Source}

National Cancer Institute. Saint Jude Children's Research Hospital. NCI Thesaurus. Code C39510.

The Saint Jude Children's Research Hospital received its NCl designation in 1977 and was awarded status as a comprehensive cancer center by $\mathrm{NCl}$ in 2008. Research is focused specifically on childhood cancers, acquired and inherited immunodeficiencies and genetic disorders. 